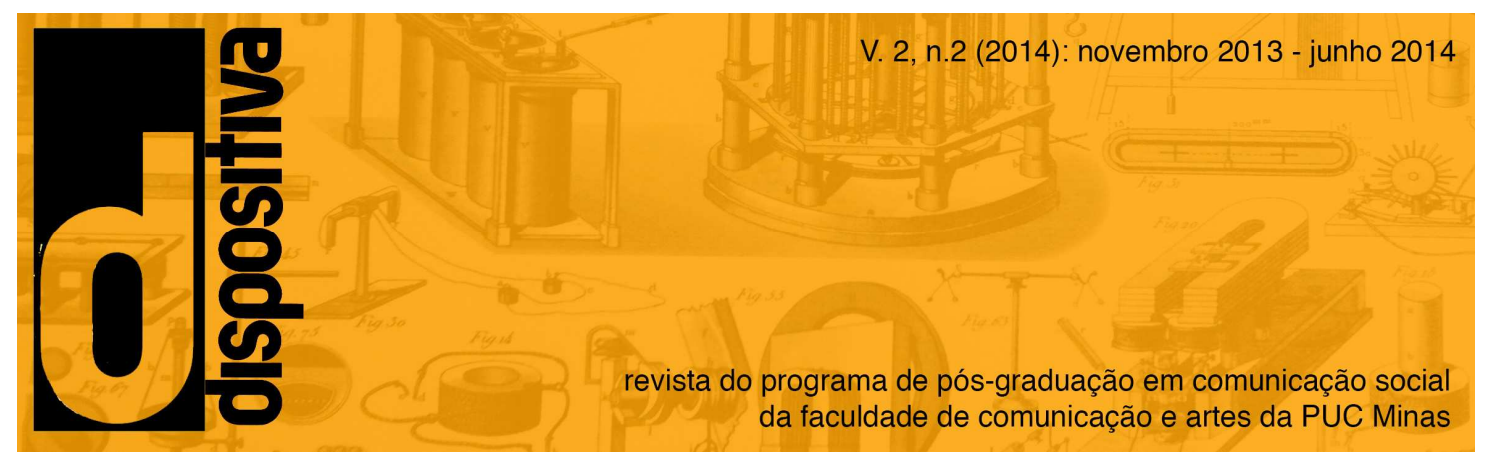

TEORIAS DO ACONTECIMENTO E CRISE ORGANIZACIONAL:

um diálogo produtivo ${ }^{1}$

EVENT THEORIES AND ORGANIZATIONAL CRISIS: a productive dialogue

Luciana de Oliveira ${ }^{2}$

Laura Luiza Tupynambá Siqueira ${ }^{3}$

Resumo: As teorias do acontecimento têm sido muito utilizadas nos estudos da comunicação, notadamente para análise do jornalismo, das celebridades, dos grandes eventos, das catástrofes. A aplicação aos estudos da comunicação organizacional é restrita, para não dizer nula. Acreditando que o entendimento das crises organizacionais pode ganhar um novo impulso com tal abordagem teórico-

1 Uma versão preliminar desse trabalho foi apresentada no Seminário Temático Comunicação Organizacional, Belo Horizonte-MG, UFMG, 27 a 29/11/2013, realizado pelo Grisorg - Grupo de Estudos em Interações e Práticas Organizacionais e pelo Grupo de Pesquisa. As reflexões nele contidas são desdobramentos da disciplina Laboratório de Planejamento de Comunicação (2/2013) e da pesquisa "A sustentabilidade como acontecimento: arqueologia de um debate em público na mídia brasileira atores, enquadramentos e valores em transição (estudo de caso sobre Belo Monte)" com financiamento do Edital MCTI/CNPq/MEC/CAPES N o 18/2012.

${ }^{2}$ Professora do Programa de Pós-Graduação e do curso de Comunicação Social da UFMG.

${ }^{3}$ Graduanda do curso de Comunicação Social da UFMG - habilitação em Relações Públicas; bolsista voluntária do Programa Iniciação Científica do Grupo de Estudos em Imagem e Socialibilidade (PICGRIS). 
metodológica, buscamos apresentar e explorar os fundamentos acerca dessa articulação, bem como os entrecruzamentos entre discursos oficiais e outros discursos presentes nas interações públicos-organizações e a propriedade da visada acontecimental para explicar fenômenos organizacionais, posto que, na situação de crise, são as organizações elas próprias acontecimentos ou catalisadoras da discussão de problemas públicos.

Palavras-chave: Acontecimento. Comunicação organizacional. Crise.

\begin{abstract}
Event theories have been extensively used in communication studies, especially to journalism, celebrities, major events, and catastrophes analysis. Its application to the studies of organizational communication is restricted, not to say non-existent. Believing that the understanding of organizational crises can gain a new impulse with such theoretical-methodological approach, we seek to present and explore the fundamentals of this connection as well as the intersections between official discourses and other discourses present in the public-organizations interactions. Similarly, we highlight the evental explanation to define organizational phenomena, given that, during a crisis, the organizations themselves are events or catalysts for the discussion of public issues.
\end{abstract}

Keywords: Event. Organizational communication. Crises.

\title{
1.Introdução
}

Um conjunto de mudanças nos modos de produzir e reproduzir as riquezas, no fazer político e na construção das relações sociais, marcou a segunda metade do século XX e consolidou-se na primeira década do século XXI. As mudanças sociais e culturais englobam a experiência estética, a transformação dos modos de vida e da paisagem urbanos, os fenômenos da mobilidade, as diversas novas formas de sociabilidade e as "teorias" cotidianas que explicam tais mudanças. Nos campos econômico e político, especialmente no que se refere aos efeitos sociológicos das transformações estruturais e organizacionais da produção de riquezas, bem como das instituições políticas, nota-se certo descolamento entre poder e política formal, da conformação de novas esferas públicas e espaços de conversações políticas que vem operando profundas transformações na forma de mobilização dos grupos e coletivos. Há também uma profunda transformação tanto da experiência quanto da reflexão sobre duas das categorias fundamentais de nosso pensamento: o espaço e o tempo. As teses do 
informacionalismo (CASTELLS, 1999), da acumulação flexível (HARVEY, 2001) e do capitalismo leve (BAUMAN, 2001) fazem eco a essas mudanças, tomando como ponto de partida as mudanças econômicas e suas implicações nos modos de pensar, viver e construir coletividades.

É claro que as três dimensões da mudança operam de forma articulada. Os efeitos podem ser vistos em diversos campos. Interessa-nos aqui destacar o quanto tais mudanças têm implicações no modo de pensar o que é uma organização e, consequentemente, nos modos de examiná-la, seja pelo alargamento necessário da noção de discurso organizacional, seja pelo esgotamento heurístico que as visões clássicas encontram frente às dinâmicas interacionais - não necessariamente harmônicas, na maior parte das vezes assimétricas e alavancadoras de disputas de poder - que configuram o próprio ser da organização. Discutiremos esse ponto na primeira parte do artigo.

Por outro lado, Silva (2011) associa a aproximação do conceito de acontecimento ao âmbito jornalístico na contemporaneidade com as significativas mudanças políticas, sociais e econômicas, além dos grandes avanços tecnológicos. A autora afirma que os acontecimentos passam a ser vividos diretamente, imediatamente, e sua divulgação não mais cabe aos historiadores e, sim, aos jornalistas e aos meios de comunicação. Não é por acaso que a relação jornalismo e acontecimento ganhou um importante impulso nas pesquisas de comunicação (TRAQUINA, 1993; SODRÉ, 2009; LEAL, ANTUNES e VAZ, 2010; FRANÇA e OLIVEIRA, 2012), considerando que é acontecimento o fato que ganha notoriedade, mas delineando inúmeras vertentes analíticas e programas de pesquisa a partir dessa constatação básica.

A grande ênfase das teorias do acontecimento desenrola-se em torno do debate acerca do acontecimento jornalístico e dos próprios fenômenos midiáticos. O uso de teorias do acontecimento na pesquisa sobre a comunicação organizacional ainda é bastante restrito. Curvello (2009) chega a defender um enfoque acontecimental para tratar dos fenômenos da comunicação organizacional, mas não se nota um efeito mais programático dessa abordagem nas pesquisas empíricas da área. Nessa seção, Dispositiva - v.2, n.2 (2014): novembro, 2013 - junho, 2014 
procuraremos compreender os acontecimentos e suas individualidades como modalidade de perspectiva teórica para pensar as crises organizacionais posto que elas são acontecimentos que colocam organizações em evidência. Tal visibilidade pode colocar em xeque a legitimidade de uma organização, pois a coloca em posição crítica frente aos públicos (GRUNIG, 2009). As organizações em crise se tornam não só objeto de uma experiência sensível, mas também objeto de uma avaliação narrativa, de uma intriga que, por sua vez, configura e reconfigura a experiência. Por isso, mais do que os discursos ou versões oficiais, há que se observar o modo como esses discursos são apropriados pelos públicos e pela opinião pública.

Os debates e conversações políticas conformados em torno de problemas organizacionais - de organizações públicas, privadas ou sociedade civil - que alcançam visibilidade pública são também parte do discurso organizacional, a partir do conceito cunhado por Baldissera (2009a; 2009b; 2010) de organização falada. O tema insere-se numa discussão sobre crise organizacional - pensando nas ações das organizações e no que elas desencadeiam do ponto de vista público. Importa dizer que não se restringe a uma abordagem convencional da crise, na maior parte das vezes de caráter normativo e técnico. A nossa proposta é tomar a crise como um acontecimento. Nessa vertente, as interações - ou seja, os modos de apropriação da informação pelos sujeitos em comunicação - são fundamentais como ponto de partida da análise sociológica a qual se pretende chegar. Para realizar o trabalho, serão resgatados os conceitos de acontecimento, campo problemático e problema público, por um lado, e por outro, a inserção neles da ideia de crise organizacional, na medida em que as organizações são elas próprias acontecimentos e, como tal, objeto de diversas apropriações pelos públicos e no espaço público. O que buscamos sublinhar é que, parece de suma importância no contexto da crise, notar como a organização é falada pois as respostas, nessa situação, não se colocam como uma invenção unilateral, mas como um diálogo.

\section{Organização e discursos organizacionais}


Normalmente, quando nos colocamos a questão: "o que é uma organização?", surgem imagens mentais que remetem a organizações concretas: empresa, escola, associação, partido político, sindicato, Estado, associação, ONG, clube, religião, etc. Do mesmo modo, quando nos colocamos o exercício conceitual de definição sobre o que é uma organização, não obstante existam vários conceitos, normalmente sobressaem-se duas explicações sociológicas. A de um grupamento planejado de pessoas que desempenham funções diferentes, mas trabalham conjuntamente em solidariedade cooperativa forjada pela necessidade de produção (DURKHEIM, 1999). Ou como um conjunto de estruturas racionais que se fundam na associação interessada de pessoas na qual vale o poder da "regra" (WEBER, 1979).

No entanto, no cenário da sociedade em rede e da liquidez/flexibilidade do capitalismo, tais visões tornam-se claramente obsoletas, já que as organizações apresentam-se, antes de mais nada, como feixes instáveis de interações que operam em lógicas de conjuntos não imediatamente reconhecíveis. A organização, assim, é uma trama de relações, mais do que um centro irradiador ou absorvedor de relações preexistentes. É mais profícuo vê-la, portanto, como um vir a ser (sob inspiração de MEAD, 1972), olhar para as interações como presentes vívidos, a um só tempo feitos de passado e prenhes de futuro que conformam os/conformam-se em contextos organizacionais. É claro que tal visão desestabiliza as lógicas de controle presentes na maior parte das organizações e as tecnologias de gestão que Ihe são corolários. Gerir, normalmente, significa gerar centros. Em dinâmicas que são descentralizadas e descontroladas por natureza, é preciso não só admitir distintos padrões de organização em co-ação como também desfazer fronteiras de atuação marcadas por um lado pelas áreas duras de tomada de decisão estratégica - racionais, instrumentais, calculistas - e áreas leves que envolvem as zonas informais, emocionais e os fluxos erráticos de informação.

Para dar conta dos processos comunicativos inscritos nas lógicas organizacionais, ou melhor, para compreender o funcionamento das organizações como redes feitas de Dispositiva - v.2, n.2 (2014): novembro, 2013 - junho, 2014 
processos comunicacionais, é preciso evocar uma abordagem relacional e interacional da comunicação. É o que defendem autores como Lima (2008), Oliveira (2009), Oliveira e Marques (2012). Tal visada defende, ancorada na abordagem da comunicação proposta por França $(2002 ; 2006)$ que a comunicação organizacional também coloca sujeitos interlocutores em relação de troca comunicacional a partir das mensagens organizacionais em um dado contexto. Para Oliveira e Marques (2012) é preciso destacar que o contexto organizacional não se restringe ao que ocorre no âmbito interno das organizações, o que normalmente costuma-se chamar de cultura organizacional ou dinâmica interna das organizações. As relações com os públicos são públicas. O contexto externo é também fundamental para o campo da comunicação organizacional em sua vertente crítica, abrindo possibilidades de encontrar o enfrentamento com as organizações pelo lado de fora do ambiente de trabalho e que o atravessam, assim como são atravessadas por dinâmicas sociais e midiáticas.

Uma das dimensões mais importantes dessa abordagem, a nosso ver, diz respeito à noção de público que ela engendra menos do que uma delimitação geográfica ou dada por um perfil socioeconômico - os quais mais se aproximam de um público imaginado pelas organizações - há uma dimensão da interação entre os sujeitos que os coloca "em público" (QUERÉ, 2003; LIMA, 2008) e não como público-alvo a ser atingido. Assim, a dimensão pública do discurso organizacional conforma os públicos - engajando-os ou alinhando-os aos objetivos organizacionais ou, ao contrário, colocando-os em conta destes. Por isso, os discursos organizacionais não se restringem aos discursos oficiais proferidos pelas organizações.

A comunicação é um processo que envolve a construção e a disputa de sentidos e, por isso, nos lembra Baldissera (2009a; 2009b; 2010), o discurso organizacional comporta pelo menos três dimensões articuladas: a organização comunicada, a organização falada e a organização comunicante. A partir de um pensamento fundado na noção de complexidade, o autor propõe que, em uma primeira dimensão, o discurso organizacional é aquele que a organização diz de si mesma, presente nos seus 
documentos públicos e em sua fala oficial. Numa segunda dimensão, coloca-se a organização comunicante, proveniente dos fluxos comunicacionais nos âmbitos formais e informais a partir das convocações propostas pela organização aos seus públicos. E, finalmente, numa terceira dimensão, está o que o autor chama de organização falada, ou seja, aquela que aciona falas nos mais diversos sujeitos e contextos em relações indiretas com a organização.

Tal concepção guarda afinidades eletivas com o chamado modelo praxiológico da comunicação que ampara certa concepção das teorias do acontecimento aplicadas aos estudos comunicacionais. Na próxima seção, exploraremos tal concepção e suas possíveis contribuições para os estudos de crise no campo da comunicação organizacional.

\section{A abordagem acontecimental e as crises organizacionais: reflexões teórico-empíricas preliminares}

Os acontecimentos fazem parte da existência de todos os sujeitos. A vida social é feita de acontecimentos - entrelaçados às nossas mais corriqueiras visões e experiências do/no mundo vivido - aos quais muitas vezes é difícil atribuir uma ordem. Como nos diz Frederich Barth (1992), em sua crítica radical ao conceito de sociedade, a vida social é caracterizada pela desordem, pelo fluxo das interações. A ordem é efeito emergente e não causa imanente. Cada indivíduo experimenta - "sofre" e reage a diferentes tipos de acontecimentos. Com diferentes intensidades, eles emolduram as conversações cotidianas e o fazer da vida coletiva entendido como um processo interminável de interações mediadas pela linguagem (MEAD, 1972; DEWEY, 2010; LATOUR, 2012). Assim, a vida coletiva é vista antes, como um processo em devir e permanente criação e recriação, do que como um ente que tenha prioridade lógica sobre os sujeitos e sua ação no mundo.

Como assinalou Aristóteles em sua Poética (citado por GEERTZ, 1978, p. 318), nossas impressões sobre o real nos chegam e permanecem, na maior parte das vezes, "frouxas 
e desorganizadas". Mas, ao mesmo tempo, encontramos elementos que de modo súbito coordenam e criam foco para essas impressões. A narrativização que ocupa os meios de comunicação - jornalística ou não, especializada ou não - segue a lógica do que Aristóteles chamou de acontecimentos típicos, posto que se propõe não só a contar o que aconteceu, mas aquilo que está sempre acontecendo. Nessa perspectiva, o acontecimento, antes conceito exclusivo dos estudos da história (SILVA, 2011), é cada vez mais estudado e discutido em diferentes campos das ciências sociais, em especial nas pesquisas em comunicação.

No contexto da comunicação, olhar para os fenômenos sob a lógica do acontecimento implica admitir que os fatos que ganham visibilidade e mobilizam um debate público podem introduzir algo de novo, não estando condicionado aquilo que os provocou. Queré $(2005 ; 2012)$ e França $(2012)$ têm buscado assinalar a potência do acontecimento em abrir o debate público sobre temas e problemas muitas vezes não visíveis e de produzir socialidade a partir das apropriações cotidianas que the imputam sentidos e se materializam por meio da sua narrativização, consolidando experiências do viver em comum de variado grau de intensidade.

A tal perspectiva, que exalta de antemão uma positividade transformadora do acontecimento por sua capacidade de afetação e exigência de narrativização, agregaríamos um vetor de poder, ressaltando também que tal processo engendra disputas de sentido ao colocar em cena vários enquadramentos de uma mesma questão e mobilizar recursos que antecedem o próprio debate midiático e nele buscam fortalecer-se. Assim, para além de prever a produção de uma nova ordem a partir do acontecimento, é preciso acentuar os antagonismos que estruturalmente perpassam as interações - não como um determinante delas, mas como algo que está em jogo e no jogo não somente de uma perspectiva exterior que as atravessa, mas como algo que está dentro dos sujeitos que a compõem - e que estabelecem, a partir do desordenamento inerente à experiência do mundo e dos outros, formas possíveis de lêlo e, consequentemente, de vivê-lo. Nesse sentido, a acontecimento contém as e está contido nas tramas da produção e também da reprodução do social. 
Considerando a ênfase ao acontecimento pelos estudos da comunicação, França (2011), resgatando diferentes pesquisas, discute sobre tipos distintos de abordagens do acontecimento. Primeiramente, destaca a concepção empirista, na qual "é a própria natureza da empiria (seu "ser") que justifica a maior ou menor importância que lhe será atribuída." (FRANÇA, 2011, P. 40). Recorrendo a autores como Queré, Verón, Charaudeau e Mouillaud, aponta, por um lado, para a abordagem construtivista do acontecimento, na qual a sua apreensão se dá como construção midiático-social, uma vez que é resultado de um processo socialmente organizado e regulado que engloba a "formatação, encenação e atribuição de sentido às informações" (FRANÇA, 2012, p. 41). Assim, os acontecimentos não existem antes do processo de construção midiática, eles só existem na medida em que pelos meios são construídos. Os processos de nomeação e transformação do fato em informação são, portanto, enfatizados. Já a abordagem ritualística é, segundo França (2011, p. 43), aquela que "de um conjunto de fatos contingentes que surgem em qualquer lugar a um momento dado, os meios extraem um media event que vai substituir ocorrências concretas reais." Dentre os eventos que recebem esse tratamento da mídia, a autora destaca a presença de acontecimentos públicos, grandes cerimônias, como uma abertura de um evento esportivo mundial; e de acontecimentos de natureza mais prosaica, como o desfecho de uma popular novela.

Várias abordagens da crise organizacional, especialmente no que se refere ao viés gerencial, vão colocá-la nessas chaves de leitura: a crise é uma fabulação midiática - seja porque é uma construção ocorrida no processo jornalístico de produção da notícia, seja porque é o resultado do enfeixamento da organização em grandes eventos, cuja natureza é negativa por ir de encontro à imagem ou à licença social que garante a ela existir. Em ambos os casos, a atitude mais correta é, segundo a normativa, esperar passivamente que a crise termine.

Limitadas por uma espécie de construcionismo midiático, tais abordagens do acontecimento negligenciam, na visão de França e em nossa visão de crise, o poder de afetação dele em suas articulações com as interações dos sujeitos sociais a partir deles. Dispositiva - v.2, n.2 (2014): novembro, 2013 - junho, 2014 
Os acontecimentos têm outra vida, para além da mídia, e que retorna a ela. Comparando a abordagem construtivista com a ritualística, França aproxima ambas as perspectivas, pois as duas substituem o acontecimento pelo modo como ele é tratado pela mídia. E as distancia na medida em que a abordagem ritualística suspende a dinâmica temporal do acontecimento, além de ser marcada por formas sociais cristalizadas, com referências compartilhadas, enquanto na construtivista são os elementos discursivos que são valorizados. Ambas, numa aproximação rápida, evocariam aquilo que Baldissera chama de organização comunicada e comunicante, pelas quais circulam os discursos oficiais e a comunicação com os públicos.

Do mesmo modo, em que há uma terceira dimensão do discurso organizacional, a organização falada, fica clara a insuficiência das abordagens previamente citadas para a apreensão de um acontecimento, incluindo as crises organizacionais. Como chama a atenção James Grunig:

\footnotetext{
(...) as pessoas controlam a utilização dos meios de comunicação muito mais do que os meios controlam o comportamento dos que os utilizam. (...) As imagens são simplesmente aquilo que as pessoas pensam e a maioria das pessoas pensa por si próprio. As pessoas constroem suas próprias visões sobre as organizações. (GRUNIG, 2003, p.71).
}

França propõe, portanto, uma terceira vertente de aproximação dos acontecimentos, levando em consideração que eles envolvem as pessoas, passando-se no domínio da experiência, realizando-se por meio de seu poder de afetação na ação dos sujeitos. Nessa linha, Queré (2005) destaca o poder hermenêutico do acontecimento que vai além da mediação da narração, evocando a noção de ação em H. Arendt e G. H. Mead. De Arendt, o autor destaca sua afirmação de que um acontecimento pode representar tanto um fim, como um início, dependendo da perspectiva adotada: de entendimento ou de ação.

Do ponto de vista do entendimento, o acontecimento é um fato que ocorre no mundo, explicável como um encadeamento; no ponto de vista da ação, o acontecimento 
é um fenômeno de ordem hermenêutica, pode ser compreendido por causas, como pode fazer compreender, revelar - uma situação problemática, por exemplo. Apoia-se na nova situação criada pelo acontecimento, sua propriedade de começo. Mas o início de uma era é o fim de outra. $\mathrm{O}$ acontecimento é partida e fecho. $\mathrm{O}$ autor ainda destaca que a contemplação pode não ser suficiente para a compreensão do acontecimento ou da situação que revela, pois passa também pela sua explicação causal. O verdadeiro acontecimento afeta alguém, que reage apropriadamente.

De Mead, evoca as reflexões sobre tempo. Quando um acontecimento se produz o mundo se altera: ele é descontinuidade visível apenas em fundo de continuidade. Queré destaca que nem tudo que acontece é descontínuo - alguns acontecimentos podem ser esperados, mas ainda sim fazem emergir algo e não são possíveis de ser controlados em sua totalidade.

Mas, destaca o autor, a maioria dos importantes acontecimentos é inesperada excedem as probabilidades previamente imaginadas, causam surpresas e motivam ações de controle. A recepção e propriedade de afetação dos acontecimentos são aspectos centrais na construção de sua individualidade: "os acontecimentos se nos assemelham. São relativos ao que nós somos, às nossas capacidades e ao nosso sentido do possível, à maneira como somos afetados e ao nosso poder de resposta, aos nossos hábitos e à nossa sensibilidade" (QUERÉ, 2005, p. 68).

Um bom exemplo da mútua afetação que uma crise organizacional pode ocasionar, é o caso da empresa Spoleto/Porta dos Fundos. Em agosto de 2012, o canal de vídeos humorísticos "Porta dos Fundos" divulgou um vídeo em que satirizava o atendimento desastroso de um empregado de uma rede de fast food de comida italiana. Logo, milhares de pessoas via redes sociais visualizaram e se identificaram com a situação de péssimo atendimento mostrada no vídeo e não tardou em aparecer um nome: o da rede de restaurantes Spoleto. Considerando a grande repercussão do vídeo e a popularidade do canal, a empresa reagiu: propôs uma parceria com os comediantes, 
incluindo o nome do restaurante e criando um novo vídeo de promoção do Serviço de Atendimento ao Consumidor da empresa. A parceria foi considerada um sucesso, com grande adesão dos consumidores na audiência e compartilhamento do novo vídeo. Após o incidente, os diretores da Spoleto foram convidados para conceder entrevistas para falar sobre superação de falhas, crise e reação.

Muito importante, portanto, considerar que acontecimentos são públicos, colocando em evidência problemas públicos e configurando campos problemáticos. A dimensão da organização falada supera, muitas vezes, os discursos oficiais. Queré (2011), ao tratar de individualização dos acontecimentos públicos, também discute acerca do conceito de acontecimento público e a relação deste com os media. Para o autor, o pensamento insatisfatório é o que atribui à mídia o papel solo de atribuir o status de público a um acontecimento ao torná-lo conhecido, via informação, configurado como convém. Para o autor, o conceito de acontecimento público é, segundo ele, mais forte em relação à primeira concepção apresentada: "o acontecimento público é fundamentalmente um acontecimento inscrito e tematizado num registro específico, o dos problemas públicos e do seu tratamento pela ação pública." (QUERÉ, 2011, p. 27). Portanto, não se deve atribuir aos media papel solo na construção de um acontecimento público. A mídia é apenas um dos componentes dos acontecimentos públicos.

Um exemplo contundente dessa apreciação é o caso que envolveu a rede de supermercados Carrefour num debate público acerca do racismo. O operário Januário Alves de Santana foi espancado por cinco homens numa loja do Carrefour em Osasco no dia 7 de agosto de 2009, sob acusação de roubar o próprio carro, porque o alarme de uma moto estacionada ao lado de onde ele estava estacionado tocou. A polícia militar foi acionada, mas os três policiais que chegaram ao local mantiveram atitude de suspeita contra Januário, dizendo: "sua cara não nega, você deve ter pelo menos três passagens pela polícia". 
Januário Alves de Santana é um homem negro. Noticiado inicialmente pela Afropress, agência de notícias ligada ao movimento negro, o caso ganhou rápida repercussão na grande mídia, nas redes sociais e por meio de intervenções e ações de protesto em várias lojas do país, além de debates na em diversos fóruns. Não é preciso dizer que a questão racial é um dos maiores gargalos político-culturais no Brasil e o fato não tardou em emergir como acontecimento por isso (não por uma construção midiática). Essa crise do Carrefour ganhou repercussão porque surge num campo problemático dos mais espinhosos em nosso contexto, fazendo parte do fenômeno, além dos media, a sua recepção em âmbito social, as operações e práticas de sujeitos individuais e coletivos bem como a incidência dos debates nos desdobramentos das ações na esfera pública.

Queré aponta que o os problemas públicos podem emergir de diferentes maneiras: de resultados de imperativos técnicos ou administrativos; de iniciativas ou de decisões políticas; dos acontecimentos da atualidade - para o autor, a fonte mais importante. Queré destaca que não só acontecimentos estão na origem de diversos problemas públicos como pela análise de um acontecimento que problemas públicos são tematizados e formulados. O autor afirma que é a partir dos inquéritos sobre acontecimentos públicos que surgem campos problemáticos nos quais eles encontram seus sentidos. Queré define campo problemático como "um conjunto de problemas enredados, cuja análise está mais ou menos estabelecida (em termos de causas e consequências, de tipos de agentes e de tipo de ação de agir) e cujo tratamento é encarado em termos de alternativas relativamente definidas." (QUERÉ, 2011, p. 27). Queré (2005) aponta que, apesar da maioria dos acontecimentos estarem inseridos em campos problemáticos já estabelecidos, em contra partida, novos campos problemáticos surgem com a emergência de outros acontecimentos. Campos problemáticos inéditos que podem atender ao propósito da construção de problemas públicos - um "agir" correto dos sujeitos. Voltando ao exemplo do Carrefour, vale dizer que o movimento negro e simpatizantes de sua causa organizaram protestos nas lojas da rede de 
supermercados, aproveitando o próprio contexto organizacional e a visibilidade alcançada pelo caso para expressar o repúdio às atitudes racistas no Brasil.

Num outro exemplo, o da Abercrombie \& Fitch, famosa marca de roupas americana que, há alguns anos, ganhou vasta adesão entre jovens brasileiros, vemos uma discussão acerca do autoritarismo de certo padrão estético de beleza emergir como campo problemático. Em 2013, a popularidade da empresa foi fortemente ameaçada após a popularização de algumas falas de seu gestor Mike Jeffries. Em maio de 2013, diversos veículos ao redor do mundo reproduziram as declarações de 2006 em que Jeffries afirma que a empresa Abercrombie \& Fitch não produz roupas de tamanhos maiores por causa de uma política da marca que deseja somente que jovens magros e "populares" a usem.

A repercussão foi grande também nas redes sociais com diversos usuários se manifestando e compartilhando links com notícias relacionadas. Após a grande mobilização e repulsa em função dos comentários anteriormente proferidos, foi divulgado, na página do facebook da empresa, um pedido de desculpas do próprio Jeffries, no qual lamenta a escolha de palavras por ele utilizadas na declaração de 2006 e reforçando que a marca é contra qualquer tipo de discriminação. Nos comentários da postagem, muitos usuários dividem posições incrédulas acerca do pedido de desculpas.

Nos meses que seguem, a empresa passa a vender alguns itens em tamanhos maiores. As ações, porém, parecem ineficazes. São realizados protestos e boicotes contra a marca e os baixos números de faturamento também são noticiados pela mídia. Em dezembro de 2013, circula na imprensa que os acionistas da empresa desejam a saída de Mark Jeffries, justificado pelo fato da queda de $30 \%$ no valor das ações. Atribui-se a essa queda, as polêmicas declarações de Jeffries e outras ações ameaçadoras à reputação da empresa no campo problemático apontado.

Vale destacar também que o acontecimento põe "em público" um assunto e uma comunidade de sujeitos. Um público surge quando determinados acontecimentos, Dispositiva - v.2, n.2 (2014): novembro, 2013 - junho, 2014 
produtos, obras projetam (estabelecem) um contexto institucional, uma situação que provoca sentido e propicia às pessoas envolvidas passar pela mesma experiência. Público, então, é o resultado de uma ação, é produzido na experiência ligada a um processo de contextualização. Para Quéré, ele não está dado de antemão - não está no início, como sujeito do verbo, desencadeando uma ação - mas é decorrência da ação (acontece durante). Para discutir esse ponto, destacamos três exemplos recentes envolvendo as empresas Renault e AT\&T.

Em fevereiro de 2007, uma consumidora adquiriu um carro da Renault em Santa Catarina. De acordo com ela, o veículo apresentou, desde os primeiros dias, problemas no funcionamento do motor. O carro foi encaminhado, nos seis meses seguintes à compra, a diversas concessionárias, mas sempre retornava com o mesmo problema. Foi constatado, por uma perícia, que o veículo apresentava um defeito de fabricação. Por ainda estar na garantia, a proprietária solicitou a montadora a devolução do dinheiro ou a troca do produto.

A Renault, porém, entrou com recursos retardando o processo. Para tornar públicas as numerosas reclamações acerca do problema, a consumidora criou, em fevereiro de 2011, o site Meu Carro Falha, além de páginas no Facebook, Orkut e Twitter e da divulgação de dois vídeos sobre o caso no Youtube. Após a divulgação nas mídias sociais, o site teve, em menos de um mês, 700.000 acessos. A montadora solicitou, então, uma liminar judicial obrigando o fechamento do site. Em março do mesmo ano, a empresa divulgou um comunicado oficial, lamentando o ocorrido, inclusive a retirada do domínio, e reforçando que tais posicionamentos não vão ao encontro dos valores da marca.

A empresa afirmou, também, que no mesmo dia foi firmado um acordo com a proprietária lesada. Hoje, o site funciona para que outros consumidores queixosos tenham onde se manifestar, destacando o sucesso da internet e mídias sociais para resolução do caso da proprietária fundadora e o poder do caso em gerar um público. 
Um público de caráter mais efêmero, mas extremamente eficaz em sua capacidade de afetação sobre uma ação de comunicação de uma organização empresarial, formou-se em torno de uma imagem publicada pela AT\&T Corporation em setembro de 2013. A empresa compartilhou no seu perfil do Twitter o que deveria ser uma homenagem às vítimas do atentado do dia 11 de setembro de 2001. A imagem retratava o memorial "Tribute in light" - dois grandes feixes de luz no local onde estavam as duas torres do World Trade Center - visto pela tela de um smartphone.

Para muitos dos seguidores da empresa na rede social, a representação era ofensiva: utilizava o momento emocional para promover telefones. Pouco mais de uma hora depois da publicação e de uma enorme repercussão negativa, a publicação original foi apagada e uma nova mensagem publicada. No novo tweet, a empresa se desculpava com quem achou a imagem de mau gosto e explicitava que era apenas uma homenagem a todos os afetados pelo atentado. A nova publicação foi também repudiada pelos usuários - não somente seguidores: na medida em que a postagem era compartilhada e novas pessoas se manifestavam sobre o assunto nas redes sociais, o acontecimento era cada vez mais publicizado. A desculpa foi interpretada como ilegítima, apenas para contenção das reações. Na manhã do dia 12 de setembro, a AT\&T publicou um novo tweet com um link para uma página na qual continha um pedido de desculpas assinado pelo diretor executivo da empresa, Randall Stepheson. Na nova mensagem de desculpas, uma manifestação mais elaborada. O erro foi assumido, os valores da empresa reafirmados: respeito pelos consumidores, pelos funcionários e pelo país.

Ao considerar os estudos sobre crise organizacional, percebe-se a constante tentativa de domesticação do acontecimento. Acontecimentos selvagens, de potencial de afetação imensurável. Acontecimentos são, como proposto por Queré, transformados em objetos e têm suas possibilidades discutidas, suas condições e consequências investigadas, provocando ação e reação. Verdade que estudiosos podem dedicar a vida para estudar os cenários de crise, mas não esgotarão as infinitas possibilidades. Os acontecimentos, cada qual com sua individualidade, são inesgotáveis. No entanto, ao Dispositiva - v.2, n.2 (2014): novembro, 2013 - junho, 2014 
pensar a crise como acontecimento, podemos analisar alguns aspectos, como os exemplos acima demonstram - a mútua afetação, a inserção em problemas públicos de relevância e a capacidade de formar públicos - que, por vezes, ficariam obscuros numa perspectiva meramente técnico-operacional.

\section{Considerações finais}

No presente artigo, discutimos que no cenário contemporâneo, marcado pela complexidade e instabilidade nas formas de produção da riqueza, da coordenação política e das relações sociais, encontramos tanto a exigência de explicação de fenômenos ligados às dinâmicas organizacionais quanto a necessidade de fazê-lo buscando abordagens comunicacionais mais robustas do que aquelas de caráter essencialmente normativo e técnico. Assim, um primeiro imperativo é uma compreensão mais alargada do que é uma organização, bem como do que é o discurso organizacional. De modo particular, buscamos em nossa reflexão aproximar a análise da comunicação organizacional, especialmente da noção de crise, das teorias do acontecimento e buscamos demonstrar o potencial heurístico de tal aproximação.

Se, por um lado, o cenário de transformações globais e fluxos de comunicação em tempo real empodera as organizações, especialmente as empresariais, também gera novas possibilidades de ação para sujeitos-cidadãos, coletivos e grupos que se colocam em atitude crítica contra as organizações. A sociedade enfrenta suas organizações, como sugerem Oliveira, Henriques e Paula, (2012), inspirados pelas reflexões acerca do sistema de resposta social de José Luiz Braga. Tal visada permite-nos observar algumas movimentações de públicos e de pessoas no espaço público, especialmente no que nos interessa aqui que são as respostas desencadeadas no contexto de crise, sugerindo tanto um outro modo de olhar para os fenômenos organizacionais quanto a necessidade de geração de outras tecnologias de gestão da comunicação nessa matéria.

Assim, a abordagem da crise como acontecimento parece garantir pelo menos três vantagens explicativas que devem ser relevadas nas pesquisas dessa área. A Dispositiva - v.2, n.2 (2014): novembro, 2013 - junho, 2014 
primeira vantagem é permitir ver a organização em movimento. Ao considerar a crise como algo que irrompe e rompe com certos modos de entendimento cristalizadas, é possível enxergar como a organização e os discursos organizacionais se fazem na mútua afetação entre organizações, públicos e opinião pública.

A segunda diz respeito ao modo como a crise "põe em público", ou seja, faz emergir coletivos, sujeitos que se organizam para falar e compartilhar suas impressões. Eles podem ser considerados como públicos pela organização ou não - sugerindo a ampliação de visões convencionais como as de públicos preferenciais, geográficos, externos, stakeholders etc. Daí a crise como uma oportunidade para visualizar a capacidade de afetação de uma organização em aglutinar interesses e despertar paixões em seu entorno. A terceira vantagem diz respeito à necessidade de olhar para o papel ético e social das organizações, na medida em que sua atuação toca em problemas públicos de relevância. Num cenário em que organizar-se é empoderar-se, tal aspecto ganha especial importância pois faz ver tanto a organização para além da organização quanto sua reflexividade sobre o próprio ser da organização.

\section{Referências}

BALDISSERA, R. A teoria da complexidade e novas perspectivas para os estudos de comunicação organizacional. In KUNSCH, M. M. K. (org.). Comunicação organizacional:histórico, fundamentos e processos. Vol.1. São Paulo: Saraiva, 2009a.

Comunicação organizacional na perspectiva da complexidade. In: Organicom: Revista Brasileira

de Comunicação Organizacional e Relações Públicas. Ano 6, ed. especial, n.10/11. (2009). São Paulo: Gestcorp-ECA-USP, Abrapcorp 2009b, (pp. 115- 120).

BATISTA, D. C. e BALDISSERA, R. Entre a organização comunicada e a "falada": a comunicação organizacional da empresa Tramontina CB. S/A. Revista Iniciacom - Vol. 2, № 2 (2010).

BARTH, F. Towards greater naturalism is conceptualizing societies. In.: KUPER, Adam. Conceptualizing Society. London, Routledge, 1992.

BAUMAN, Z. Modernidade Líquida. Rio de Janeiro, Jorge Zahar Editores, 2001.

CASTELLS, M. A Sociedade em Rede. São Paulo, Paz e Terra, 1999. 
CURVELLO, J.J.A. A comunicação organizacional como fenômeno, como processo e como sistema. Revista Organicom, Ano 6, n. 10/11, 2009 (edição especial).

DEWEY, J. Ter uma experiência. In: Arte como experiência. São Paulo: Martins Fontes, 2010, p.109142.

DURKHEIM, E. Da Divisão do Trabalho Social. São Paulo, Martins Fontes, 1999.

FRANÇA, Vera; OLIVEIRA, Luciana de (Org.). Acontecimento: reverberações. Belo Horizonte: Autêntica Editora, 2012.

FRANÇA, V.R.V.. O acontecimento para além do acontecimento: uma ferramenta heurística. In: FRANÇA, Vera; OLIVEIRA, Luciana de (Org.). Acontecimento: reverberações. Belo Horizonte: Autêntica Editora, 2012.

FRANÇA, V.R.V.. O crime e o trabalho de individuação do acontecimento no espaço midiático. In: Caleidoscópio: Revista de Comunicação e Cultura. Lisboa, Edições Universitárias Lusófonas, n. 10, p. 41$58,1^{\circ}$ sem. 2011.

GEERTZ, C. A Interpretação das Culturas. Rio de Janeiro, Jorge Zahar, 1978.

HARVEY, D. Condição Pós-Moderna. 10a ed. São Paulo, Edições Loyola, 2001.

GRUNIG, J. A função das relações públicas na administração e sua contribuição para efetividade organizacional e societal. Revista Comunicação \& Sociedade, Vol. 1, No 39 (2003). Disponível em: http://200.144.189.42/ojs/index.php/cs umesp/article/view/142/102 Acesso em 03/01/2013.

LATOUR, B. Reagregando o social: uma introdução à teoria do ator-rede. Salvador/Bauru, EDUFBA/EDUSC, 2012.

LEAL, B; VAZ, P. B.; ANTUNES, R. De quem é a agenda? In: BENETTI, M; FONSECA, V. P. S. Jornalismo e acontecimento: mapeamentos críticos. Florianópolis: Insular, 2010, p.221-239.

LIMA, F. "Possíveis Contribuições do Paradigma Relacional para o estudo da Comunicação no contexto organizacional". In: OLIVEIRA, I. de L. e SOARES, A. T. Interfaces e Tendências da Comunicação no Contexto das Organizações. São Caetano do Sul, Difusão, 2008.

MEAD, G. H. Espiritu, persona y sociedad desde el punto de vista del conductivismo social. 3a ed. Buenos Aires, Paidos, 1972.

OLIVEIRA, I. de L. Objetos de estudo da comunicação organizacional e das relações públicas: um quadro conceitual. Revista Organicom, Ano 6 (Edição Especial), números 10/11, 2009.

OLIVEIRA, I. HENRIQUES, M.S. e PAULA, M. A. de. A sociedade enfrenta suas organizações? Interação entre organizações e sociedade nas mídias sociais articulada pelo discurso da sustentabilidade. Revista Esferas, Ano 1, no 1, julho a dezembro de 2012. 
OLIVEIRA, L; MARQUES, A. A imagem de organizações públicas e o sentido de público no discurso de charges sobre Belo Monte. Líbero (FACASPER), v. 15, p. 59-70, 2012.

QUERÉ, L. “Le public comme forme et comme modalité d’experiénce". In: CEFAÏ, D. e PASQUIER, D. (Dir.). Le sens du public: publics politiques, publics médiatiques. Paris, Presses Universitaires de France, 2003. Entre facto e sentido: a dualidade do acontecimento. In: Trajectos - Revista de Comunicação, Cultura e Educação. Lisboa, no 6, 2005, p. 59-76.

A dupla vida do acontecimento: por um realismo pragmatista. In: FRANÇA, Vera; OLIVEIRA, Luciana de (Org.). Acontecimento: reverberações. Belo Horizonte: Autêntica Editora, 2012.

A individualização dos acontecimentos no quadro da experiência pública. In: Caleidoscópio: Revista de Comunicação e Cultura. Lisboa, Edições Universitárias Lusófonas, n. 10, p. 41-58, 1 sem. 2011.

SILVA, C. M. T. Perspectivas acerca do conceito "acontecimento". In: Caleidoscópio: Revista de Comunicação e Cultura. Lisboa, Edições Universitárias Lusófonas, n. 10, p. 41-58, $1^{\circ}$ sem. 2011.

SODRÉ, Muniz. A narração do fato: notas para uma teoria do acontecimento. Editora Vozes, Petropolis, 2009.

TRAQUINA, Nelson. Jornalismo: questões, teorias e estórias. Lisboa: Vega, 1993.

WEBER, Max. Os três tipos puros de dominação legítima. In: Weber. Sociologia. Coleção Grandes Cientistas Sociais, n. 13. São Paulo, Ática, 1979.

Sites consultados (casos citados)

Caso AT\&T

http://newyork.cbslocal.com/2013/09/11/att-pulls-tweet-showing-smartphone-with-911-memorial/

http://arstechnica.com/business/2013/09/att-distastefully-combines-911-memorial-with-a-smartphone-

ad/

http://depaulcorpcomm.com/post/65411273171/at-ts-tribute-in-light-fail

Caso Spoleto

http://www.youtube.com/watch?v=ebe-

3s4TLfQ\&list=PLTOSmhj8chMX08ghdLpZwvAGLaxr0s8Sk\&index=14

http://www.youtube.com/watch?v=fGyt3sF3T7M\&list=PLTOSmhj8chMX08ghdLpZwvAGLaxrOs8Sk 
http://www.estadao.com.br/noticias/impresso,o-humor-na-web-como-estrategia-de-

marketing,1028871,0.htm

Caso Abercrombie \& Fitch

http://rollingstone.uol.com.br/canal/fashion/acionistas-da-abercrombrie-fitch-querem-demissao-de-ceo

http://juromano.com/moda/polemica/depois-da-polemica-abercrombie-perde-a-credibilidade

http://vogue.globo.com/moda/moda-news/noticia/2013/05/polemica-ceo-da-abercrombie-nao-querconsumidores-gordos-diz-autor.html

Caso Meu Carro Falha/Renault

http://quatrorodas.abril.com.br/noticias/proprietaria-lesada-pela-renault-mobilizainternet-284629 p.shtml

http://www.meucarrofalha.com.br/arquivos internos/index.php?abrir=sobre site

\section{Caso Carrefour}

http://www.estadao.com.br/noticias/cidades, acusado-de-roubar-seu-carro-cliente-eespancado-em-mercado, $421145,0 . \mathrm{htm}$

http://www.afropress.com/post.asp?id=11605

http://www.afropress.com/post.asp?id=11606 